\title{
Does Teriparatide Improve Fracture Union?: A Systematic Review
}

\author{
Byung-Ho Yoon', Ki-Choul Kim² \\ 'Department of Orthopaedic Surgery, Seoul Paik Hospital, Inje University College of Medicine, Seoul; \\ ${ }^{2}$ Department of Orthopaedic Surgery, Dankook University Hospital, Dankook University College of Medicine, Cheonan, Korea
}

\author{
Corresponding author \\ Ki-Choul Kim \\ Department of Orthopaedic Surgery, Dankook \\ University Hospital, Dankook University \\ College of Medicine, 201 Manghyang-ro, \\ Dongnam-gu, Cheonan 31116, Korea \\ Tel: +82-41-550-6290 \\ Fax: +82-41-556-0524 \\ E-mail: puhoo73@hanmail.net
}

Received: August 13, 2020

Revised: August 25, 2020

Accepted: August 26, 2020
We conducted an updated review of the evidence of teriparatide (TPTD) for fracture healing for the following questions. (1) Does it decrease fracture healing time?; (2) Can it be an alternative treatment for nonunion?; (3) Does it aid the union of atypical femoral fracture (AFF)? We searched PubMed, EMBASE, and Cochrane Library including "Fracture" AND "nonunion" AND "Teriparatide". In total, 57 publications met our inclusion criteria were summarized. This systemic review of the available literature revealed that TPTD works positively with regard to enhancing fracture healing time and union of AFF. There are also many case studies on the use of TPTD could be a potential new safe treatment for nonunion with no side effects. However, level 1 studies on the evidence of TPTD are still lacking so far. Over the last decade, a growing body of evidence has accumulated suggesting that TPTD can be an adjunct to enhance fracture healing or a therapeutic option to treat nonunion, but greater evidences from large volume prospective trials are needed.

Key Words: Fractures, bone · Parathyroid hormone - Teriparatide

\section{INTRODUCTION}

Nonunion is the most frequent cause of reoperation and highly morbid complication as burden of fracture. The biologic process of fracture healing is complex and impacted by multiple factors, and this is prevalent in certain risk groups such as elderly, osteoporosis, in people with malnutrition.[1,2] At present, no pharmacologic treatments are available for nonunion, so there is an unmet need for medications that can stimulate bone healing.

Teriparatide (TPTD), a synthetic polypeptide hormone of the recombinant human parathyroid hormone is considered to be the most potent of the osteoporosis therapies with its marketed anabolic effect.[3] However, there has been a great interest in using TPTD to enhance fracture healing or to treat nonunion is off-label with potent bone-forming effects.[4,5] The existing basic science data suggest TPTD accelerate chondrocyte recruitment and differentiation, which are essential processes in early enchondral ossification.[6,7] Thus TPTD enhance fracture healing by improving the biomechanical properties of the fracture callus, increasing both cartilaginous and mineralized callus formation. Its anabolic effect is given by the stimulation of the osteoblast, and fibroblast growth factor 2 is also up-regu-

\section{Mineral Research}

This is an Open Access article distributed under the terms of the Creative Commons Attribution Non-Commercial License (https://creativecommons.org/licenses/by-nc/4.0/) which permits unrestricted non-commercial use, distribution, and reproduction in any medium, provided the original work is properly cited.

\section{KSBMR}


lated in TPTD treated individuals.[8-10]

There has been previous reviews that suggest the role of TPTD as alternate to induce fracture healing.[11-13] However, to date, many clinical trials have been undertaken to elucidate the efficacy of TPTD for inducing fracture healing in several situations, such as atypical femoral fracture (AFF). [14-16] A better understanding of the role of TPTD with greater evidences on fractures healing could help clinician to make their decision.

Thus, we conducted an updated review to evaluate the efficacy of TPTD on fracture healing. (1) Does it decrease fracture healing time?; (2) Can it be an alternative treatment for nonunion?; (3) Does it aid the union of AFF?

\section{LITERATURE REVIEW}

This review was conducted according to the updated guidelines of the Preferred Reporting Items for Systematic Review and Meta-Analysis Protocols.[17] A multiple database search including PubMed, EMBASE, and Cochrane Library was performed using the search terms: ("recombi- nant human parathyroid hormone 1-34" [All Fields] OR "recombinant human parathyroid hormone 1-84" [All Fields] OR "teriparatide" [All Fields] OR "abaloparatide" [All Fields] OR "Forsteo" [All Fields] OR "Teribone" [All Fields]) AND ("fractures, bone" [MeSH Terms] OR ("fractures" [All Fields] AND "bone" [All Fields]) OR "bone fractures" [All Fields] OR "osteoporotic fracture" [All Fields]) between 1 January 1960 and 31 June 2020.

Studies were eligible for inclusion if patients were treated with daily 20 or $40 \mu \mathrm{g}$ of recombinant human parathyroid hormone (PTH; 1-34) or weekly $56.5 \mu \mathrm{g}$ to induce fracture healing or nonunion. We excluded patients with illnesses that affect bone or calcium metabolism underwent surgical treatment for pathologic fracture. After screening the studies identified by the search, 113 citations relevant articles were reviewed, and 57 key publications were selected (Fig. 1).

\section{Does TPTD decrease the fracture healing time?}

Shortening the healing time can be important, especial-

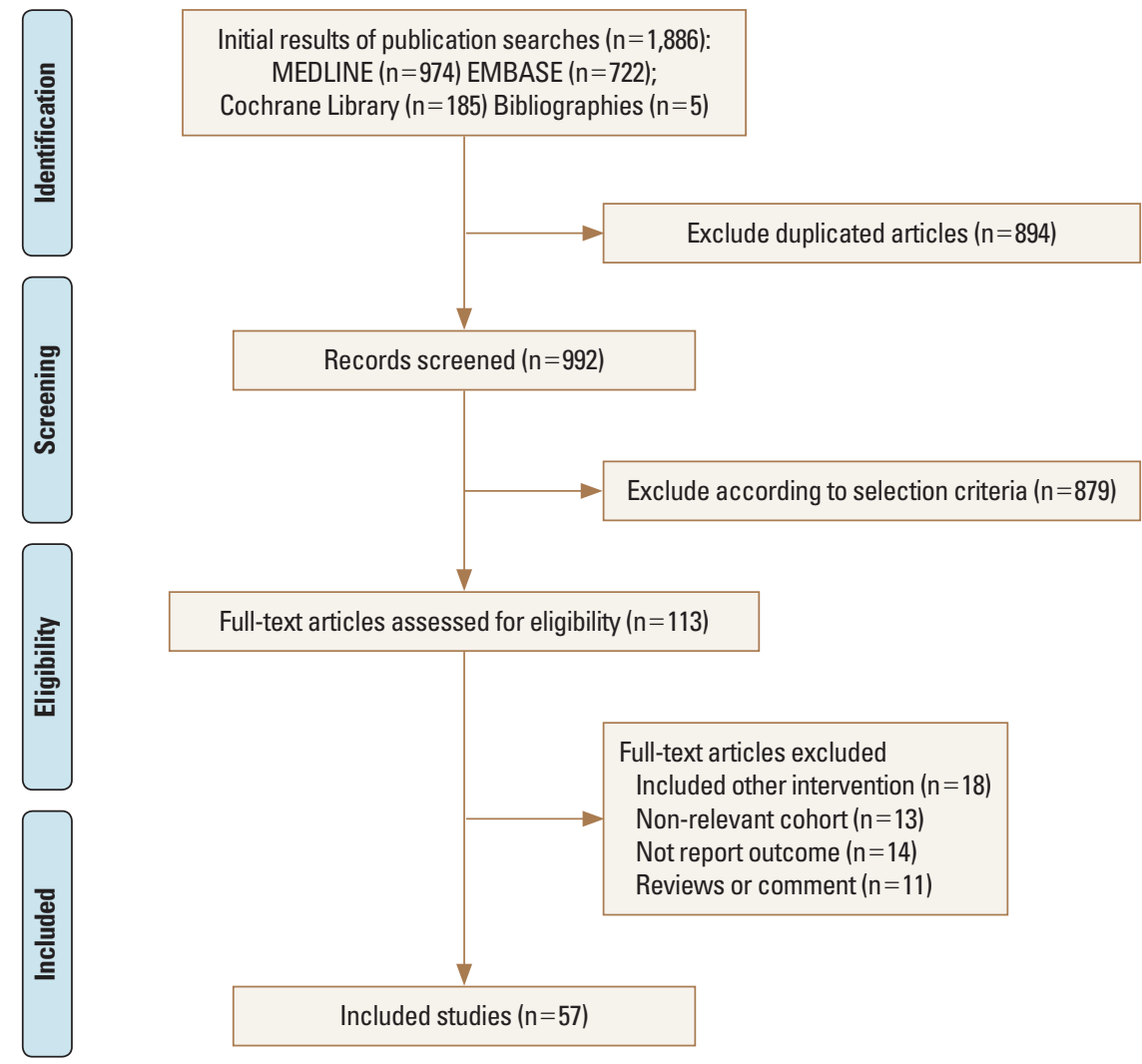

Fig. 1. Flow chart showing the publications included in this study. 
ly for elderly patients, who have a long healing time. For example, intertrochanteric fractures are usually fixed enough to load-bearing, but each step is painful over many weeks until the fracture is healed.[18,19] TPTD is occasionally used off-label to accelerate fracture healing and has been reported to improve mechanical properties of fracture callus, bone-implant contact, and strength at the fracture site. $[15,20]$

There were 2 studies that showed that short-term daily TPTD use improved radiographic fracture healing of a hip fracture and reduced complication rates. Huang et al. [21] retrospectively reviewed 255 intertrochanteric fractures (AO type 31-A1 fractures and limited to patients treated using a dynamic hip screw). A significantly shorter time-tounion (mean, 12.3 vs. 10.6 weeks, respectively $[P=0.002]$ ) and improved pain function score were found in the TPTDtreated groups [21] Kim et al. [22] retrospectively assessed 112 unstable intertrochanteric fractures that had been treated using proximal femoral nail and a daily subcutaneous injection of TPTD was used in 52 of 112 patients. TPTD significantly decreased mean time to fracture healing (12.1 vs. 14.8 weeks; $P=0.002)$ and VAS pain scores $(P=0.008)$ and increased function score $(P=0.02)$. The frequency of patients reporting postoperative surgery-related complications was also markedly lower in the TPTD-treated groups in both studies.[22,23]

Intermittent TPTD administration also has been reported to accelerate pelvic fracture and distal radial fracture healing by enhancing callus formation.[24-26] Sixty-five patients who had been treated with pelvic fractures divided into 21 patients received a once-daily injection of $100 \mathrm{mg}$ of PTH 1-84, and 44 patients served as the control group. At week 8 , all fractures in the treatment group and 4 fractures in the control group had healed (healing rate, 100\% vs. 9.1\%) and mean pain and function score (time up and go test, 22.9 vs. $54.3 \mathrm{sec} ; P<0.001$ ), even nonunion was not detected at the latest visit.[27]

To date, 2 meta-analyses have been performed to determine the effectiveness of TPTD on fracture healing time, and their results were in conflict. One meta-analysis of patients with osteoporotic fractures found a significantly shorter healing time in the TPTD-treated group.[28] Another meta-analysis, including nonosteoporotic fractures did not demonstrate effectiveness for TPTD with regard to faster union, but only 2 studies were analyzed in this meta-anal- ysis.[29]

One study reported radiographic features of TPTD-induced healing in femoral insufficiency fracture.[30] Callus formation was found at a very early stage at 2 weeks after treatment. Moreover, abundant callus formation was found circumferentially around the cortex with a 'cloud-like' appearance. They also found that normal remodeling of the TPTD-induced callus was observed on plain radiographs after 1 year. These findings indicate that TPTD can be used as an adjuvant therapy as induce in the management of femoral insufficiency fractures.[31,32]

We believed that clinicians may still expect that TPTD use can contribute to fracture healing time and functional recovery in osteoporotic fracture patients. It is still not known whether a standard dose or duration of TPTD is optimal, and these results were limited by the paucity of the randomized studies, so more high-quality randomized controlled trials (RCTs) are still needed.[33]

\section{Can TPTD be an alternative for nonunion?}

The nonunion of fractures remains a challenging and clinically important problem in orthopaedic surgery. In the last years, many case reports about the efficacy of the use of TPTD off-label in the therapy of nonunions were presented.[34-37]

Many cases have reported the successful use of TPTD in many different fracture nonunion sites such as: the sternum, odontoid, radius, humerus, femur, and ulna and even Charcot arthropathy.[35,37-41] Treating nonunions with TPTD could be of great interest mainly because it allows patients to avoid another surgery and autograft associated problems, such as donor site pain or neurovascular injury. $[42,43]$ In addition to its effectiveness in treating nonunion, there were no side effects that occurred in all case reports during the follow-up period. Several animal studies have shown that PTPD by dual mechanism of action, influencing both bone formation activity and bone resorption.[8, $9,44,45]$ PTPD up-regulate gene markers associated with osteoblast differentiation and an inhibitor of the Wnt pathway.[6,46]

Successful attempt to use of TPTD even after revision surgery of nonunion has been published.[47] Surgeons can be very frustrated when nonunion not allowing its healing even if revision is well-performed according to the principles (surgical restabilization and provision of biological 
stimulation).[48,49] A 45-year-old man with femoral shaft fracture nonunion at which the original intramedullary nail was revised with internal fixation using an anatomical plate together with autogenous bone graft. However, reoperation again failed to heal the fracture in the next 12 months. Successful union was obtained after once-daily administration ( $20 \mu \mathrm{g} /$ day) of TPTD for 9 months. This report highlights the needs for prospective randomized clinical trials with larger patient groups to compare the effectiveness of TPTD and autogenous bone grafting in treating fracture non-union.[43,47,50]

The accumulated evidence suggests that TPTD treatment can enhance fracture healing, but the optimal timing, treatment duration, dose, dosing interval, and form of TPTD remain uncertain.[51-54] In humans, PTH doses that are approved to treat postmenopausal osteoporosis: $20 \mathrm{mg} /$ day TPTD (4.9 nmoles, in the US) or $100 \mathrm{mg} /$ day PTH 1-84 (10.6 nmoles, in Europe). With regard to the form and dose of PTH, most reports describe the use of daily TPTD. The reported TPTD treatments at $20 \mu \mathrm{g} /$ day for 3 to 9 months resulted in a successful union in all reports (Table 1).

Periprosthetic fracture after arthroplasty also considered as a fracture with a high risk of nonunion, especially in elderly patients with severe osteoporosis. Thus, TPTD is widely used to preserve or improve periprosthetic bone mineral density after total knee arthroplasty (TKA) or total hip arthroplasty for osteoporotic patients.[55] Several reports suggest that TPTD may give a further boost in healing process in periprosthetic fracture.[14,56] One case report has shown that nonunion of periprosthetic fracture after TKA, that occurred even after the patient underwent internal fixation and bone grafting twice, was successfully fused after simple administration of once-weekly TPTD.[53]
Based on the recent reports, the use of TPTD can be a promising treatment to improve the healing of nonunion, when fracture environments do not permit its healing. However, the general principles in the treatment of nonunion mandatory and infection also should be excluded before the use of TPTD.

\section{Does TPTD aid the union of AFF?}

There are several studies that TPTD treatment can aid fracture healing in patients with AFF.[57-60] One retrospective study compared 2 groups, AFFs were treated TPTD $(\mathrm{n}=21)$ and not-TPTD $(\mathrm{n}=24)$ groups. All TPTD group showed faster healing time ( $5.4 \pm 1.5$ vs. $8.6 \pm 4.7$ months; $P=0.012$ ), and low frequency of delayed healing or nonunion $(P=0.012)$. [61] Yeh et al. [62] also retrospectively examined 13 female patients with a total of 16 AFFs that all treated with an intramedullary fixation and divided into 2 groups (8 AFFs in TPTD-treated group vs. 8 in non-TPTD group). The mean time to bone union was shorter in the TPTD-treated group (4.4 vs. 6.2 months; $P=0.116$ ), and union rate within 6 months was also higher in the TPTD-treated group (75\% [6/8] vs. $50 \%$ [4/8]; $P=0.3$ ) achieved.

In 1 prospective study involving 14 consecutive AFF patients, 5 patients treated with TPTD for 6 months was associated with increased bone remodelling and partial or complete healing of atypical fractures and pain relief.[63] TPTD might increase bone remodeling resulting in the removal of more completely mineralised bone and replacement with newly synthesized and less densely mineralised bone. [12] One multicenter study retrospectively reviewed 46 AFFs from 7 institutions, and TPTD decreased the time to union (24.9 vs. 19.7 weeks; $P=0.08$ ).[1]

But the studies are not sufficiently powered because

Table 1. Review of case studies which reported successful treatment of nonunion by use of teriparatide

\begin{tabular}{lclccccc}
\hline References & Year & \multicolumn{1}{c}{ Site } & $\begin{array}{c}\text { Age of } \\
\text { patient (yr) }\end{array}$ & Type of nonunion & $\begin{array}{c}\text { Use of } \\
\text { teriparatide }\end{array}$ & $\begin{array}{c}\text { Duration of } \\
\text { treatment } \\
\text { (months) }\end{array}$ & $\begin{array}{c}\text { Time to complete } \\
\text { union after therapy } \\
\text { (months) }\end{array}$ \\
\hline Tsai and Hu [34] & 2019 & Femur shaft & 60 & Atrophic & $20 \mu \mathrm{g} / \mathrm{d}$ & 6 & 6 \\
Yu and Guo [47] & 2017 & Femur shaft & 45 & Hypertrophic & $20 \mu \mathrm{g} / \mathrm{d}$ & 9 & 6 \\
Xiaofeng et al. [51] & 2017 & Femur and tibia shaft & 44 & Hypertrophic & $20 \mu \mathrm{g} / \mathrm{d}$ & 8 & 12 \\
Mancilla et al. [52] & 2015 & Femur and tibia shaft & $19-64$ & Atrophic & $20 \mu \mathrm{g} / \mathrm{d}$ & $3-9$ & $3-9$ \\
Mitani [54] & 2013 & Femur neck & 88 & Atrophic & $56.5 \mu \mathrm{g} / \mathrm{wk}$ & 9 & 6 \\
Ochi et al. [53] & 2013 & Periprosthetic fracture & 74 & Atrophic & $20 \mu \mathrm{g} / \mathrm{d}$ & 6 & 3 \\
Giannott et al. [36] & 2013 & Distal femur metaphysis & 80 & Atrophic & $20 \mu \mathrm{g} / \mathrm{d}$ & 3 & 3 \\
Lee et al. [35] & 2012 & Femur neck and shaft & $29-64$ & Oligotrophic/Atrophic & $20 \mu \mathrm{g} / \mathrm{d}$ & $3-9$ & $3-9$ \\
\hline
\end{tabular}


they were all case reports and case series and there is still a lack of level 1 studies on the evidence of TPTD in promoting bone healing in AFF. It is difficult to set up an adequately powered study because of the low incidence of AFF and healing of AFF can be affected by variables such as lower limb geometry (greater curvature of the femoral diaphysis) and location of fracture (subtrochanteric or diaphysis).[6466] Above all, these results should be implied that TPTD works best when the fracture site is stable, either inherently or with surgical fixation. $[67,68]$

The European Calcified Tissue Society suggested the use of TPTD after surgery of AFFs, even though strong evidence for improved fracture union is lacking.[59] However, there is a clear need for RCTs to evaluate whether TPTD enhances the union of AFF may contribute to the risk of AFF.

\section{CONCLUSIONS}

Although TPTD might reduce the risk of nonunion, it appears from animal data as well as the present study that the main clinical advantage of using TPTD would be an acceleration of time to fracture healing and enhanced bone formation. Thus, one could hypothesize the possibility of medical treatment with TPTD both as a preventive way and also as a support to the synthesis in high risk of nonunion fractures and complexed fractures in osteoporotic bone.

\section{DECLARATIONS}

\section{Ethics approval and consent to participate Not applicable.}

\section{Conflict of interest}

No potential conflict of interest relevant to this article was reported.

\section{ORCID}

Byung-Ho Yoon https://orcid.org/0000-0001-8518-6331

Ki-Choul Kim https://orcid.org/0000-0002-7012-0695

\section{REFERENCES}

1. Lee KJ, Yoo JJ, Oh KJ, et al. Surgical outcome of intramedullary nailing in patients with complete atypical femoral fracture: a multicenter retrospective study. Injury 2017;48:
941-5.

2. Yoo Jl, Ha YC, Ryu HJ, et al. Teriparatide treatment in elderly patients with sacral insufficiency fracture. J Clin Endocrinol Metab 2017;102:560-5.

3. Blick SK, Dhillon S, Keam SJ. Teriparatide: a review of its use in osteoporosis. Drugs 2008;68:2709-37.

4. Cosman F. The evolving role of anabolic therapy in the treatment of osteoporosis. Curr Opin Rheumatol 2019;31: 376-80.

5. Burkard D, Beckett T, Kourtjian E, et al. Effects of bone remodeling agents following teriparatide treatment. Osteoporos Int 2018;29:1351-7.

6. Lin EA, Liu CJ, Monroy A, et al. Prevention of atrophic nonunion by the systemic administration of parathyroid hormone (PTH 1-34) in an experimental animal model. J Orthop Trauma 2012;26:719-23.

7. Geusens P, Marin F, Kendler DL, et al. Effects of teriparatide compared with risedronate on the risk of fractures in subgroups of postmenopausal women with severe osteoporosis: the VERO trial. J Bone Miner Res 2018;33:783-94.

8. Rowshan HH, Parham MA, Baur DA, et al. Effect of intermittent systemic administration of recombinant parathyroid hormone (1-34) on mandibular fracture healing in rats. J Oral Maxillofac Surg 2010;68:260-7.

9. Tao ZS, Lv YX, Cui W, et al. Effect of teriparatide on repair of femoral metaphyseal defect in ovariectomized rats. Z Gerontol Geriatr 2016;49:423-8.

10. Shin YH, Shin WC, Kim JW. Effect of osteoporosis medication on fracture healing: an evidence based review. J Bone Metab 2020;27:15-26.

11. Cappuzzo KA, Delafuente JC. Teriparatide for severe osteoporosis. Ann Pharmacother 2004;38:294-302.

12. Im Gl, Lee SH. Effect of teriparatide on healing of atypical femoral fractures: a systemic review. J Bone Metab 2015; 22:183-9.

13. Kim SM, Kang KC, Kim JW, et al. Current role and application of teriparatide in fracture healing of osteoporotic patients: a systematic review. J Bone Metab 2017;24:65-73.

14. Ippolito G, Ferraro $S$, Zitiello M, et al. Shoulder periprosthetic fracture in elderly patient: a minimally invasive osteosynthesis and "off-label" treatment with teriparatide. A case report and literature review. J Biol Regul Homeost Agents 2019;33:57-62.

15. Sugimoto T, Shiraki M, Fukunaga M, et al. 24-month openlabel teriparatide once-weekly efficacy research trial ex- 
amining bone mineral density in subjects with primary osteoporosis and high fracture risk. Adv Ther 2017;34:172740.

16. Miyauchi A, Matsumoto T, Sugimoto T, et al. Effects of teriparatide on bone mineral density and bone turnover markers in Japanese subjects with osteoporosis at high risk of fracture in a 24-month clinical study: 12-month, randomized, placebo-controlled, double-blind and 12-month openlabel phases. Bone 2010;47:493-502.

17. Shamseer L, Moher D, Clarke M, et al. Preferred reporting items for systematic review and meta-analysis protocols (PRISMA-P) 2015: elaboration and explanation. BMJ 2015; 350:g7647.

18. Kanakaris NK, West RM, Giannoudis PV. Enhancement of hip fracture healing in the elderly: evidence deriving from a pilot randomized trial. Injury 2015;46:1425-8.

19. Yoon BH, Park IK, Kim Y, et al. Incidence of nonunion after surgery of distal femoral fractures using contemporary fixation device: a meta-analysis. Arch Orthop Trauma Surg 2020. http://dx.doi.org/10.1007/s00402-020-03463-x.

20. Babu S, Sandiford NA, Vrahas M. Use of teriparatide to improve fracture healing: what is the evidence? World J Orthop 2015;6:457-61.

21. Huang TW, Chuang PY, Lin SJ, et al. Teriparatide improves fracture healing and early functional recovery in treatment of osteoporotic intertrochanteric fractures. Medicine (Baltimore) 2016;95:e3626.

22. Kim SJ, Park HS, Lee DW, et al. Short-term daily teriparatide improve postoperative functional outcome and fracture healing in unstable intertrochanteric fractures. Injury 2019;50:1364-70.

23. Bansal T, Sharma V, Farooque K. Short-term daily teriparatide improve postoperative functional outcome and fracture healing in unstable intertrochanteric fractures. Injury 2020;51:1137.

24. Moon SW, Lee DH, Kim YC, et al. Parathyroid hormone 1-34 (teriparatide) treatment in pelvic insufficiency fractures-a report of two cases. J Bone Metab 2012;19:147-51.

25. Aspenberg P, Genant HK, Johansson T, et al. Teriparatide for acceleration of fracture repair in humans: a prospective, randomized, double-blind study of 102 postmenopausal women with distal radial fractures. J Bone Miner Res 2010;25:404-14.

26. Suhm N, Egger A, Zech C, et al. Low acceptance of osteoanabolic therapy with parathyroid hormone in patients with fragility fracture of the pelvis in routine clinical practice: a retrospective observational cohort study. Arch Orthop Trauma Surg 2020;140:321-9.

27. Peichl P, Holzer LA, Maier R, et al. Parathyroid hormone 1-84 accelerates fracture-healing in pubic bones of elderly osteoporotic women. J Bone Joint Surg Am 2011;93:1583-7.

28. Lou S, Lv H, Wang G, et al. The effect of teriparatide on fracture healing of osteoporotic patients: a meta-analysis of randomized controlled trials. Biomed Res Int 2016;2016: 6040379.

29. Shi Z, Zhou H, Pan B, et al. Effectiveness of teriparatide on fracture healing: a systematic review and meta-analysis. PLoS One 2016;11:e0168691.

30. Kim Y, Tanaka C, Tada H, et al. Radiographic features of teriparatide-induced healing of femoral fractures. Bone Rep 2015;3:11-4.

31. Kasukawa Y, Miyakoshi N, Ebina T, et al. Enhanced bone healing and decreased pain in sacral insufficiency fractures after teriparatide treatment: retrospective clinicalbased observational study. Clin Cases Miner Bone Metab 2017; 14:140-5.

32. Wu CC, Wei JC, Hsieh CP, et al. Enhanced healing of sacral and pubic insufficiency fractures by teriparatide. J Rheumatol 2012;39:1306-7.

33. Bhandari $M$, Jin $L$, See $K$, et al. Does teriparatide improve femoral neck fracture healing: results from a randomized placebo-controlled trial. Clin Orthop Relat Res 2016;474: 1234-44.

34. Tsai MH, Hu CC. Teriparatide as nonoperative treatment for femoral shaft atrophic nonunion: a case report. World J Clin Cases 2019;7:2838-42.

35. Lee YK, Ha YC, Koo KH. Teriparatide, a nonsurgical solution for femoral nonunion? A report of three cases. Osteoporos Int 2012;23:2897-900.

36. Giannotti S, Bottai V, Dell'Osso G, et al. Atrophic femoral nonunion successfully treated with teriparatide. Eur J Orthop Surg Traumatol 2013;23 Suppl 2:S291-4.

37. Marin F. Treatment of chronic nonunion of a sternal fracture with teriparatide. Ann Thorac Surg 2020. http://dx. doi.org/10.1016/j.athoracsur.2020.05.026.

38. Oteo-Alvaro A, Moreno E. Atrophic humeral shaft nonunion treated with teriparatide (rh PTH 1-34): a case report. J Shoulder Elbow Surg 2010;19:e22-8.

39. Bednar DA. Teriparatide treatment of a glucocorticoid-associated resorbing nonunion of a type III odontoid pro- 
cess fracture: a case report. J Spinal Disord Tech 2013;26: E319-22.

40. Uemura T, Okada M, Yokoi T, et al. Successful bone healing of nonunion after ulnar shortening osteotomy for smokers treated with teriparatide. Orthopedics 2015;38:e733-7.

41. Tamai K, Takamatsu K, Kazuki K. Successful treatment of nonunion with teriparatide after failed ankle arthrodesis for Charcot arthropathy. Osteoporos Int 2013;24:2729-32.

42. Yoon BH, Lee JK, Choi DS, et al. Prevalence and associated risk factors of sarcopenia in female patients with osteoporotic fracture. J Bone Metab 2018;25:59-62.

43. Shimada Y, Ishikawa T, Endo J, et al. Treatment of atypical ulnar fractures associated with long-term bisphosphonate therapy for osteoporosis: autogenous bone graft with internal fixation. Case Rep Orthop 2017;2017:8602573.

44. Komrakova M, Hoffmann DB, Nuehnen V, et al. The effect of vibration treatments combined with teriparatide or strontium ranelate on bone healing and muscle in ovariectomized rats. Calcif Tissue Int 2016;99:408-22.

45. Murphy CM, Schindeler A, Cantrill LC, et al. PTH (1-34) treatment increases bisphosphonate turnover in fracture repair in rats. J Bone Miner Res 2015;30:1022-9.

46. Borges JL. Accelerated fracture healing with teriparatide. Arch Endocrinol Metab 2015;59:89.

47. Yu W, Guo X. Teriparatide treatment of femoral fracture nonunion that autogenous bone grafting failed to heal: a case report. Arch Osteoporos 2017;12:15.

48. Canintika AF, Dilogo IH. Teriparatide for treating delayed union and nonunion: a systematic review. J Clin Orthop Trauma 2020;11:S107-12.

49. Chintamaneni S, Finzel K, Gruber BL. Successful treatment of sternal fracture nonunion with teriparatide. Osteoporos Int 2010;21:1059-63.

50. Qiu Z, Wei L, Liu J, et al. Effect of intermittent PTH (1-34) on posterolateral spinal fusion with iliac crest bone graft in an ovariectomized rat model. Osteoporos Int 2013;24: 2693-700.

51. Xiaofeng L, Daxia X, Yunzhen C. Teriparatide as a nonoperative treatment for tibial and femoral fracture nonunion: a case report. Medicine (Baltimore) 2017;96:e6571.

52. Mancilla EE, Brodsky JL, Mehta S, et al. Teriparatide as a systemic treatment for lower extremity nonunion fractures: a case series. Endocr Pract 2015;21:136-42.

53. Ochi K, Ikari K, Naomi A, et al. Administration of teriparatide treatment for a challenging case of nonunion of peri- prosthetic fracture after total knee arthroplasty. Arch Osteoporos 2013;8:159.

54. Mitani Y. Effective treatment of a steroid-induced femoral neck fracture nonunion with a once-weekly administration of teriparatide in a rheumatoid patient: a case report. Arch Osteoporos 2013;8:131

55. Suzuki T, Sukezaki F, Shibuki T, et al. Teriparatide administration increases periprosthetic bone mineral density after total knee orthroplasty: a prospective study. J Arthroplasty 2018;33:79-85.

56. Miura T, Kijima H, Tani T, et al. Two cases of periprosthetic atypical femoral fractures in patients on long-term bisphosphonate treatment. Case Rep Surg 2019;2019:9845320.

57. Feron JM, Cambon-Binder A. Medication management after intramedullary nailing of atypical fractures. Injury 2017; 48 Suppl 1:S15-7.

58. Shane E, Burr D, Abrahamsen B, et al. Atypical subtrochanteric and diaphyseal femoral fractures: second report of a task force of the American Society for Bone and Mineral Research. J Bone Miner Res 2014;29:1-23.

59. van de Laarschot DM, McKenna MJ, Abrahamsen B, et al. Medical management of patients after atypical femur fractures: a systematic review and recommendations from the European calcified tissue society. J Clin Endocrinol Metab 2020;105:1682-99.

60. Tsuchie H, Miyakoshi N, Iba K, et al. The effects of teriparatide on acceleration of bone healing following atypical femoral fracture: comparison between daily and weekly administration. Osteoporos Int 2018;29:2659-65.

61. Miyakoshi N, Aizawa T, Sasaki S, et al. Healing of bisphosphonate-associated atypical femoral fractures in patients with osteoporosis: a comparison between treatment with and without teriparatide. J Bone Miner Metab 2015;33: 553-9.

62. Yeh WL, Su CY, Chang CW, et al. Surgical outcome of atypical subtrochanteric and femoral fracture related to bisphosphonates use in osteoporotic patients with or without teriparatide treatment. BMC Musculoskelet Disord 2017;18:527.

63. Chiang CY, Zebaze RM, Ghasem-Zadeh A, et al. Teriparatide improves bone quality and healing of atypical femoral fractures associated with bisphosphonate therapy. Bone 2013;52:360-5.

64. Khow KS, Shibu P, Yu SC, et al. Epidemiology and postoperative outcomes of atypical femoral fractures in older adults: a systematic review. J Nutr Health Aging 2017;21:83- 
91.

65. Blum L, Cummings K, Goulet JA, et al. Atypical femur fractures in patients receiving bisphosphonate therapy: etiology and management. Eur J Orthop Surg Traumatol 2016; 26:371-7.

66. Lee YK, Kim TY, Ha YC, et al. Atypical subtrochanteric fractures in Korean hip fracture study. Osteoporos Int 2017;28: 2853-8.
67. Kim JW, Kim JJ, Byun YS, et al. Factors affecting fracture location in atypical femoral fractures: a cross-sectional study with 147 patients. Injury 2017;48:1570-4.

68. Min BW, Koo KH, Park YS, et al. Scoring system for identifying impending complete fractures in incomplete atypical femoral fractures. J Clin Endocrinol Metab 2017;102:54550. 